\section{nephron \\ Clinical}

Practice
Nephron 2017;137:306-309

DOI: $10.1159 / 000484113$
Received: June 2, 2017

Accepted: October 5, 2017

Published online: November 13, 2017

\title{
Care of the Acute Kidney Injury Survivor
}

\author{
Ron Wald $^{\mathrm{a}}$ Abhijat Kitchlu $^{\mathrm{a}}$ Ziv Harel $^{\mathrm{a}}$ Samuel A. Silver ${ }^{\mathrm{b}}$ \\ ${ }^{a}$ Division of Nephrology, St. Michael's Hospital and University of Toronto, Toronto, ON, Canada; \\ ${ }^{\text {b}}$ Division of Nephrology, Queen's University, Kingston, ON, Canada
}

\section{Keywords}

Acute kidney injury · Ambulatory care · Survivor

\begin{abstract}
While the short-term implications of acute kidney injury (AKI) have been known for many years, far less attention has been paid to the health of AKI survivors. This was perhaps fueled by a prevailing wisdom that if a patient was fortunate enough to survive the primary illness associated with AKI, the prognosis for future health was auspicious. More recently, this dogma was challenged by data suggesting that after an episode of AKl, patients remain at risk of experiencing multiple adverse health outcomes. Greater recognition and appreciation of the risks faced by AKI survivors have led to the development of quality improvement initiatives that are supposed to enrich this vulnerable population.
\end{abstract}

(c) 2017 S. Karger AG, Basel

Contribution from the AKI and CRRT 2017 Symposium at the 22nd International Conference on Advances in Critical Care Nephrology, Manchester Grand Hyatt, San Diego, Calif., USA, March 7-10, 2017. This symposium was supported in part by the NIDDK funded University of Alabama at Birmingham-University of California San Diego O'Brien Center for Acute Kidney Injury Research (P30 DK079337).

\section{KARGER}

() 2017 S. Karger AG, Basel

E-Mail karger@karger.com

www.karger.com/nef

\section{The Acute Kidney Injury Survivor: A Proposed Definition}

There is no consensus with regard to the time frame as to when a patient who experienced an episode of acute kidney injury (AKI) is declared a "survivor". While the Acute Dialysis Quality Initiative has recently proposed a new paradigm for AKI recovery, this was mainly focused on the kidney component of the patient's illness [1]. For the purpose of this review, we broadly define the "AKI survivor" as an individual who has achieved some degree of global clinical stability following the acute illness that led to his/her AKI. This includes discharge from the acute hospitalization, but our definition allows for the possibility of persisting kidney dysfunction.

\section{All-Cause Mortality after AKI}

For patients surviving the initial phase of their AKIassociated acute illness, it remains somewhat controversial whether an AKI episode independently associates with heightened long-term mortality. In a cohort of patients with dialysis-requiring AKI (AKI-D) who sur-

\footnotetext{
Dr. Ron Wald

Division of Nephrology, St. Michael's Hospital

61 Queen Street East

9-140 Toronto, ON M5C 2T2 (Canada)

E-Mailwaldr@smh.ca
} 
vived till the time of discharge and became independent of dialysis, mortality over the ensuing years was $>30 \%$, but when compared to a propensity score-matched cohort of hospital survivors without AKI, AKI-D was not independently associated with mortality [2]. In a separate study that focused on survivors of AKI-associated hospitalizations who did not receive dialysis, a modest relationship between AKI and long-term death was observed [3]. Though it is reasonable to debate whether there is a true causal relationship between AKI and death, there is no doubt that AKI survivors have a high mortality in the months and years following their initial AKI episode.

\section{Chronic Kidney Disease and AKI}

Numerous studies have highlighted the connection between $\mathrm{AKI}$ and the subsequent identification of chronic kidney disease (CKD). AKI-D survivors who became dialysis independent in the short term were 3 times more likely to progress to chronic dialysis as compared to matched patients who did not experience AKI [2]. A more extensive body of data supports a compelling link between AKI and de novo non-dialysis-dependent CKD. Bucaloiu et al. [4] demonstrated a nearly twofold risk of new CKD even after ostensible resolution of AKI. Over a 12-month follow-up of US veterans with AKI and persistent kidney dysfunction, it was found that approximately $50 \%$ developed new CKD [5]. Despite this, less than $10 \%$ of these patients were referred to a nephrologist. Chawla et al. [6] examined kidney outcomes following AKI more comprehensively by evaluating major adverse kidney events (defined as the composite of death, dialysis and a sustained decline in estimated glomerular filtration rate of 25\%). Compared to a referent group of patients hospitalized with a myocardial infarction, patients with an episode of AKI had a more than twofold adjusted risk of a major adverse kidney event. Though ostensibly compelling, there are important caveats to consider before ascribing a causal mechanism to the relationship between AKI and CKD. First, AKI and CKD share common risk factors (e.g., diabetes, cardiovascular disease) and the relationship between AKI and CKD may be confounded by these. Furthermore, the lag time between AKI and subsequent established CKD may be prolonged; it is entirely possible that intervening events (e.g., episodes of heart failure, recurrent sepsis) to which AKI survivors might be predisposed may have been the "true" mediators of CKD.

\section{Cardiovascular Disease in AKI Survivors}

The association between AKI and vascular health has been the subject of several recent studies. In a cohort of 43,611 normotensive patients hospitalized in the Kaiser Permanente of Northern California healthcare network between 2008 and 2011, AKI, which developed in 6\% of patients, was associated with a $22 \%$ higher risk of new onset hypertension (adjusted odds ratio [aHR] 1.22, $95 \%$ CI 1.12-1.33) in the subsequent 2 years [7]. The severity of the initial AKI episode was associated with the likelihood of the patient being diagnosed with hypertension.

Several studies have highlighted the relationship between AKI and subsequent myocardial infarction [8], stroke [9] and heart failure [10, 11]. Most recently, Chawla et al. [6] highlighted that among veterans admitted with a myocardial infarction, super-imposed AKI during the index hospitalization portended a higher risk of major adverse cardiovascular events (defined as the composite of stroke, heart failure or recurrent myocardial infarction) over the ensuing follow-up that extended to 6 years (aHR 1.24, 95\% CI 1.18-1.30 as compared to patients with a myocardial infarction uncomplicated by AKI) [6].

\section{Resource Utilization}

The significant healthcare costs attributed to AKI have been reported recently [12]. Potentially preventable re-presentations to the healthcare system after an episode of AKI may mitigate these costs. In a study of $>150,000$ patients hospitalized with AKI in Ontario, Canada, we showed that readmissions to hospital within 30 days were significantly more likely (aHR 1.53, 95\% CI 1.50-1.57) among AKI survivors relative to propensity score-matched patients without AKI [13]. Using Veterans' Administration data, Siew et al. [14] further demonstrated a $25 \%$ cumulative incidence of recurrent AKI with the majority of such events occurring within the first 90 days from discharge after the initial AKI-related hospitalization. Key risk factors for recurrent AKI included older age, pre-existing comorbidities (CKD, diabetes, coronary disease and dementia), specific etiologies of the index hospitalization (heart failure, malignancy) and the receipt of chemotherapy on the index hospitalization. 


\section{Quality of Life}

The Acute Renal Failure Trials Network investigators rigorously evaluated quality of life among 415 trial participants, all of whom had AKI-D, who survived to 60 days after randomization [15]. Health utility was poor overall, but most sobering was the fact that $27 \%$ of survivors had a health utility of 0 , rating their life as being equivalent to or worse than being dead. Health utility also associated with mortality during the subsequent 10 months [16]. However, other studies that followed AKI-D survivors for up to several years suggested no difference in quality of life as compared to other critically ill patients $[17,18]$.

\section{Strategies to Improve Outcomes among AKI Survivors}

The optimal follow-up of AKI survivors is controversial particularly due to the lack of evidence-based interventions specific to this population. The Kidney Disease Improving Global Outcomes AKI guidelines recommend that kidney function be checked 90 days after an episode of AKI in order to ascertain whether CKD can be formally diagnosed [19]. Compliance with this recommendation has been incomplete [20]. Early follow-up of AKI survivors might be of conceivable benefit by specifically targeting the health risks that these patients face. Harel et al. [21] studied nearly 4,000 Ontarians with AKI-D who were discharged from hospital off dialysis. Only $41 \%$ of these individuals saw a nephrologist during the 90 days following discharge. In a propensity-matched analysis, a visit with a nephrologist associated with $25 \%$ lower risk of death during the years that ensued (aHR 0.76, 95\% CI $0.62-0.93)$.

The notion of early nephrology follow-up potentially enhancing outcomes for AKI survivors spurred the establishment of AKI follow-up clinics at various institutions [22]. The key features of each clinic (e.g., model of care, criteria for referral, duration of time from discharge to follow-up) are variable. At our centre (St. Michael's Hospital, Toronto, Canada), we have targeted individuals who were hospitalized with KDIGO stage 2 or 3 AKI with the intent of an initial clinic visit within 30 days after hospital discharge. We have focused our attention on individuals not previously followed by nephrologists and those without conditions (e.g., glomerulonephritis, polycystic kidney disease) that would mandate routine nephrology follow-up.
Subsequently, patients attend clinic at intervals determined by the attending nephrologist but for no longer than one year at which time the patient is either referred back to his/her primary care physician or for ongoing nephrology follow-up depending on the patient's kidney function.

The assessments and interventions provided at our clinic were derived in response to the specific aforementioned risks faced by AKI survivors. Blood pressure management, albuminuria control and cardiovascular risk reduction are cornerstones of clinic visits with the intent of optimizing kidney and cardiovascular outcomes. Medication reconciliation, which includes the re-initiation of medications stopped during the acute illness and the discontinuation (or dose modification) of existing medications in light of the patient's current kidney function, is emphasized. This is coupled with "sick day" medication cessation advice for drugs such as renin-angiotensin-aldosterone system blockers and diuretics in order to mitigate the risk of recurrent AKI.

Though intuitively attractive, the provision of routine post-AKI care requires rigorous evaluation. A multicentre randomized controlled trial comparing early standardized follow-up by a nephrologist to usual care is underway (Clinicaltrials.gov: NCT02483039). As the results of this trial are awaited, several caveats of nephrologistled post-AKI follow-up require consideration. First, it is unclear which subset of the AKI population should be preferentially targeted. Given the high prevalence of AKI, a widespread policy of follow-up for all AKI survivors is impracticable. Furthermore, the basket of interventions provided as well as the frequency and duration of followup will require better delineation.

In conclusion, AKI survivors face a wide array of important health challenges. Recognition of AKI survivors as a high-risk group deserving of closer medical attention may improve patient outcomes and reduce healthcare costs by averting potentially preventable events.

\section{Financial Support}

This study was partially funded by a grant provided by the Ontario Academic Health Sciences Centre Alternate Funding Plan Innovation (R.W. and S.A.S.).

\section{Disclosure Statement}

The authors have no conflicts of interest to declare. 


\section{References}

-1 Chawla LS, Bellomo R, Bihorac A, Goldstein SL, Siew ED, Bagshaw SM, Bittleman D, Cruz D, Endre Z, Fitzgerald RL, Forni L, Kane-Gill SL, Hoste E, Koyner J, Liu KD, Macedo E, Mehta R, Murray P, Nadim M, Ostermann M, Palevsky PM, Pannu N, Rosner M, Wald R, Zarbock A, Ronco C, Kellum JA; Acute Disease Quality Initiative Workgroup 16: Acute kidney disease and renal recovery: consensus report of the Acute Disease Quality Initiative (ADQI) 16 Workgroup. Nat Rev Nephrol 2017;13:241-257.

-2 Wald R, Quinn RR, Luo J, Li P, Scales DC, Mamdani MM, Ray JG; University of Toronto Acute Kidney Injury Research Group: Chronic dialysis and death among survivors of acute kidney injury requiring dialysis. JAMA 2009; 302:1179-1185.

$>3$ Wald R, Quinn RR, Adhikari NK, Burns KE, Friedrich JO, Garg AX, Harel Z, Hladunewich MA, Luo J, Mamdani M, Perl J, Ray JG; University of Toronto Acute Kidney Injury Research Group: Risk of chronic dialysis and death following acute kidney injury. Am J Med 2012;125:585-593.

4 Bucaloiu ID, Kirchner HL, Norfolk ER, Hartle JE 2nd, Perkins RM: Increased risk of death and de novo chronic kidney disease following reversible acute kidney injury. Kidney Int 2012;81:477-485.

$\checkmark 5$ Siew ED, Peterson JF, Eden SK, Hung AM, Speroff T, Ikizler TA, Matheny ME: Outpatient nephrology referral rates after acute kidney injury. J Am Soc Nephrol 2012;23:305-312.

$\checkmark 6$ Chawla LS, Amdur RL, Shaw AD, Faselis C, Palant CE, Kimmel PL: Association between $\mathrm{AKI}$ and long-term renal and cardiovascular outcomes in United States veterans. Clin J Am Soc Nephrol 2014;9:448-456.

$\checkmark 7$ Hsu CY, Hsu RK, Yang J, Ordonez JD, Zheng S, Go AS: Elevated BP after AKI. J Am Soc Nephrol 2016;27:914-923.
$>8$ Wu VC, Wu CH, Huang TM, Wang CY, Lai CF, Shiao CC, Chang CH, Lin SL, Chen YY, Chen YM, Chu TS, Chiang WC, Wu KD, Tsai PR, Chen L, Ko WJ; NSARF Group: Longterm risk of coronary events after AKI. J Am Soc Nephrol 2014;25:595-605.

$\checkmark 9$ Wu VC, Wu PC, Wu CH, Huang TM, Chang CH, Tsai PR, Ko WJ, Chen L, Wang CY, Chu TS, Wu KD; National Taiwan University Study Group on Acute Renal Failure (NSARF) Group: The impact of acute kidney injury on the long-term risk of stroke. J Am Heart Assoc 2014;3:pii:e000933.

10 Gammelager H, Christiansen CF, Johansen MB, Tønnesen E, Jespersen B, Sørensen HT: Three-year risk of cardiovascular disease among intensive care patients with acute kidney injury: a population-based cohort study. Crit Care 2014;18:492.

11 Odutayo A, Wong CX, Farkouh M, Altman DG, Hopewell S, Emdin CA, Hunn BH: AKI and long-term risk for cardiovascular events and mortality. J Am Soc Nephrol 2017;28:377-387.

12 Silver SA, Long J, Zheng Y, Chertow GM: Cost of acute kidney injury in hospitalized patients. J Hosp Med 2017;12:70-76.

13 Silver SA, Harel Z, McArthur E, Nash DM, Acedillo R, Kitchlu A, Garg AX, Chertow GM, Bell CM, Wald R: 30-Day readmissions after an acute kidney injury hospitalization. Am J Med 2017;130:163-172.e164.

14 Siew ED, Parr SK, Abdel-Kader K, Eden SK, Peterson JF, Bansal N, Hung AM, Fly J, Speroff T, Ikizler TA, Matheny ME: Predictors of recurrent AKI. J Am Soc Nephrol 2016;27: 1190-1200.

-15 Johansen KL, Smith MW, Unruh ML, Siroka AM, O'Connor TZ, Palevsky PM; VA/NIH Acute Renal Failure Trial Network: Predictors of health utility among 60-day survivors of acute kidney injury in the veterans affairs/ national institutes of health acute renal failure trial network study. Clin J Am Soc Nephrol 2010;5:1366-1372.

16 Joyce VR, Smith MW, Johansen KL, Unruh ML, Siroka AM, O’Connor TZ, Palevsky PM; Veteran Affairs/National Institutes of Health Acute Renal Failure Trial Network: Healthrelated quality of life as a predictor of mortality among survivors of AKI. Clin J Am Soc Nephrol 2012;7:1063-1070.

17 Vaara ST, Pettila V, Reinikainen M, Kaukonen KM; Finnish Intensive Care C: Populationbased incidence, mortality and quality of life in critically ill patients treated with renal replacement therapy: a nationwide retrospective cohort study in Finnish intensive care units. Crit Care 2012;16:R13.

18 Oeyen S, De Corte W, Benoit D, Annemans L, Dhondt A, Vanholder R, Decruyenaere J, Hoste E: Long-term quality of life in critically ill patients with acute kidney injury treated with renal replacement therapy: a matched cohort study. Crit Care 2015;19:289.

19 KDIGO: clinical practice guideline for acute kidney injury. Kidney Int 2012;2(suppl 1):1138.

20 Matheny ME, Peterson JF, Eden SK, Hung AM, Speroff T, Abdel-Kader K, Parr SK, Ikizler TA, Siew ED: Laboratory test surveillance following acute kidney injury. PLoS One 2014;9:e103746.

-21 Harel Z, Wald R, Bargman JM, Mamdani M, Etchells E, Garg AX, Ray JG, Luo J, Li P, Quinn RR, Forster A, Perl J, Bell CM: Nephrologist follow-up improves all-cause mortality of severe acute kidney injury survivors. Kidney Int 2013;83:901-908.

-22 Silver SA, Goldstein SL, Harel Z, Harvey A, Rompies EJ, Adhikari NK, Acedillo R, Jain AK, Richardson R, Chan CT, Chertow GM, Bell CM, Wald R: Ambulatory care after acute kidney injury: an opportunity to improve patient outcomes. Can J Kidney Health Dis 2015;2:36. 